Jurnal SPORTIF: Jurnal Penelitian Pembelajaran

Vol. 6 No. 2, Agustus 2020, pp. 423-438

doi) https://doi.org/10.29407/js_unpgri.v6i2.14497

\title{
Resiliensi siswa tunanetra dalam kegiatan olahraga
}

\section{Sport resilience in students with visual impairment}

\section{Akhmad Olih Solihin', Agi Ginanjar², dan Dena Widyawan ${ }^{3}$}

\begin{abstract}
${ }^{1}$ Department of Physical Education Health and Recreation, STKIP Pasundan, Street of Permana No. 32B, Citeureup, Cimahi Regency, West Java Province, 40512, Indonesia ${ }^{2}$ Department of Physical Education Health and Recreationi, STKIP Nahdlatul Ulama Indramayu, Street of Raya Kaplongan No. 28, Kaplongan, Karangampel, Indramayu Regency, West Java Province, 45283, Indonesia

${ }^{3}$ Department of Physical Education Health and Recreation, STKIP Situs Banten, Street of Bayangkara, Cipocok Jaya, Serang City, Bante Provincen, 42121, Indonesia
\end{abstract}

Received: 22 June 2020; Revised: 21 July 2020; Accepted: 2 August 2020

\begin{abstract}
Abstrak
Salah satu faktor siswa tunanetra dapat disebabkan sejak lahir. Siswa tunenetra kurang mendapatkan kesempatan terlibat dalam berbagai aspek dalam kehidupan, khususnya dalam kegiatan olahraga. Walaupun siswa tunantera tetap mengikuti kegiatan olahraga, bagaimana resiliensi mereka agar tetap mengikuti kegiatan olahhraga. Tujuan dari penelitian ini adalah untuk mengetahui resiliensi siswa tunanetra dari lahir dalam berolahraga di Sekolah Luar Biasa (SLB). Metode penelitian yang digunakan melalui pendekatan kualitatif dengan studi kasus. Partisipan terdiri dari kepala sekolah, wakil kepala sekolah, guru pendidikan jasmani, guru kelas, dan 2 siswa tunanetra dari lahir di SLB Negeri A Citereup Kota Cimahi, sehingga partisipan yang terlibat sebanyak 5 orang partisipan. Instrummen penelitian menggunakan wawancara dan observasi. Analisi data di bantu dengan menggunakan aplikasi NVivo 12 Plus. Hasil penelitian menyatakan bahwa resiliensi siswa tunanetra dalam kegiatan olahraga hanya sebatas mengikuti instruksi dan tidak memenuhi rekomendasi aktivitas fisik. Untuk menjaga agar siswa tunanetra mau berolahraga dengan memberikan nasihat, motivasi, bimbingan konseling secara individu, dan melakukan kegiatan olahraga di waktu luang.
\end{abstract}

Kata kunci: resiliensi, siswa tunanetra, olahraga.

\begin{abstract}
One of the factors causing visual impairments (disabilities) is physical deficiencies from birth. Students with visual disabilities do not have the same opportunity to be involved in many life activities including in sports activities. Students with visual disabilities can still participate in sports and their resilience to keep participating is important to be studied. The purpose of this study is to determine the Sport resilience of students with visual impairment in special schools (SLB). The research method used is qualitative approach with case studies. Participants consist of the principal, deputy principal, physical education teacher, classroom teacher, and 2 students with visual impairment in SLB Negeri A Citereup Cimahi. The total participants are 5 people. The research instruments are interviews and observations. Data analysis is assisted by NVivo 12 Plus application. The result of the study shows that sport resilience in students with visual impairment is inadequate because they only follow the instructions and do not obey physical activity recommendations. To improve their willingness
\end{abstract}

Correspondence author: Akhmad Olih Solihin, STKIP Pasundan, Indonesia.

Email: akhmad_olih@stkippasundan.ac.id 
participating in physical exercise, several methods can be applied are delivering positive advice and enthusiasm, providing individual counseling, and encouraging them to do exercise in their spare time.

Keywords: resilience, students with visual impairment, sports.

\section{PENDAHULUAN}

Kaum disabilitas perlu untuk mendapatkan perhatian dan bantuan dari kita semua yang masih normal, tetapi pada kenyataannya banyak masyarakat yang memiliki cara pandang berbeda dalam menyikapi keberadaan disabilitas sekarang ini. Ditambah lagi dengan keberadaan ekonomi yang rendah, semakin terkucilkan dan tersisihkan di dalam setiap kegiatan masyarakat. $90 \%$ orang dengan kebutaan atau penglihatan sebagian di negara-negara berpenghasilan rendah sebagian besar dari mereka sangat tidak berdaya dan dikeluarkan dari kegiatan berbasis masyarakat (Ajuwon \& Bieber, 2014).

Salah satu disabilitas adalah tunanetra (gangguan penglihatan). Kurang dari dua persen anak-anak dan remaja dengan gangguan penglihatan di negara berpenghasilan rendah memiliki akses terhadap segala bentuk pendidikan atau pelatihan. Klingberg menyatakan kurangnya akses ini merupakan tantangan yang berat bagi keseluruhan upaya untuk memperbaiki kondisi sekitar 1,4 juta anak tunanetra di dunia saat ini (Ajuwon \& Bieber, 2014). Anak-anak ini memiliki gangguan penglihatan berdampak pada kesempatan mereka untuk mendapatkan pendidikan, pekerjaan, rekreasi, dan potensi penghasilan. Gangguan penglihatan dapat mempengaruhi perkembangan global anak-anak (aspek motorik, kognitif dan psikososial), menahan partisipasi mereka dalam kegiatan sosial, dan umumnya memperburuk kualitas hidup mereka (Lupón, Armayones, \& Cardona, 2018). Padahal dengan diberikannya akses pendidikan dan pelatihan kepada penyandang disabilitas mereka akan merasakan penerimaan yang lebih tinggi terhadap disabilitas mereka karena pendidikan yang mereka terima dan bukan hanya karena kebijakan publik (Kaur, Leong, Yusof, \& Singh, 2015).

Kebutaan berarti gangguan dalam penglihatan yang mempengaruhi kinerja pendidikan anak, istilah ini mencakup penglihatan sebagian dan 
kebutaan (National Dissemination Center for Children with Disabilities, 2012). Faktor penyebab ketunanetraan terdiri dari dua. Pre-natal sangat erat hubungannya dengan keturanan dan pertumbuhan anak dalam kandungan seperti hasil perkawinan sedarah, sesama tunanetra, orang tua yang tunanetra, gangguan waktu ibu hamil, penyakit menahun seperti TBC, rubella, tumor, kekurangan vitamin. Post-natal terjadi setelah bayi lahir seperti: kerusakan mata waktu persalinan, ibu mengalami penyakit gonorrhoe, mengalami penyakit mata seperti trachoma, dan akibat kecelakaan. Dampak ketunanetraan dapat berpengaruh pada perkembangan keterampilan akademis, khususnya dalam bidang membaca dan menulis. Orang yang sama sekali tidak dapat melihat dan melihat sebagian tidak mampu menggunakan penglihatannya untuk membaca dalam keadaan cahaya normal (Mir'atannisa, 2017). Sebagai contoh, ketika anda membaca atau menulis anda tidak perlu memperhatikan secara rinci bentuk huruf atau kata, tetapi bagi tunanetra hal tersebut tidak bisa dilakukan karena ada gangguan pada ketajaman penglihatannya. Ditengah permasalahan tersebut, mereka harus tetap bertahan untuk menjalani kehidupan.

Resiliensi atau ketahanan adalah kemampuan individu untuk menavigasi jalan mereka ke sumber daya psikologis, sosial, budaya, dan fisik yang menopang kesejahteraan mereka, dan kapasitas mereka secara individu dan kolektif untuk menegosiasikan agar sumber daya ini disediakan dan dialami dengan cara yang bermakna secara budaya (Sharma \& Sen, 2012; Ungar, 2012). Pemahaman ekologis tentang resiliensi menempatkannya sebagai proses yang ditentukan oleh "sifat ekologi sosial dan fisik anak, proses interaksi antara lingkungan dan individu anak, dan kecenderungan spesifik anak menuju perkembangan positif (Ungar, 2011).

Resiliensi pada tunanetra sangat penting dan harus dimiliki oleh setiap individu tunanetra, karena dengan resiliensi akan menentukan berhasil atau tidaknya tunanetra dalam mencapai pendidikan yang layak bahkan untuk dapat berperan dalam kehidupan di masyarakat. Ada 
banyak hal yang bisa dilakukan, salah satunya dengan mengoptimalkan indera yang lain, misalnya pendengaran, penciuman, ataupun perabaan (Izzudin, 2006). Anak tunanetra memiliki kebutuhan perkembangan dan fisik yang sama dengan anak normal. Mereka memiliki kebutuhan aktivitas fisik yang sama. Karakteristik emosianal mereka, kebutuhan untuk menguasai lingkungan dan kebutuhan diri tidak berbeda dengan anak lain yang berbeda hanyalah intensitasnya. Kebutuhan bergerak dan aktivitas fisik merupakan kebutuhan yang sangat penting karena tanpa kegiatan tersebut dunia (lingkungan) akan terbatas pada jangkauan tangan-tangan. Kegiatan fisik bagi tunanetra dapat juga digunakan sebagai perlindungan diri seperti misalnya berlari untuk menghindari bahaya. Kemampuan untuk bangkit dan berdiri pada saat jatuh atau menggulingkan badannya merupakan salah satu kegiatan fisik untuk melindungi dari bahaya yang lain.

Hasil penelitian terdahulu menyatakan bahwa resiliensi yang tinggi berkorelasi dengan harga diri, kebahagiaan, kesejahteraan, dan kecemasan rendah (Dahlbeck \& Lightsey, 2008). Dalam pendidikan resiliensi telah berkorelasi negatif dengan kelelahan akademik (Rahmati, 2015). Resiliensi tinggi berkorelasi dengan kinerja akademik yang kuat, komunikasi yang efektif, dan partisipasi aktif dalam kegiatan (Ahlert \& Greeff, 2012). Lebih lanjut lagi bahwa resiliensi berkorelasi positif dengan keberhasilan akademik pada siswa tunarungu atau tunanetra (Butler, Katayama, Schindling, \& Dials, 2016).

Resiliensi seorang tunanetra dapat terlihat dalam beberapa keadaan, tempat dan waktu. Salah satu tempat dan waktu untuk mendapat gambaran resiliensi pada seorang tunanetra ialah ketika di sekolah pada saat pembelajaran pendidikan jasmani yang menggunakan aktivitas olahraga, karena ketika berolahraga siswa dapat bertingkah lebih natural dan ekpresif dibanding pembelajaran lainnya, ini terjadi disebabkan mata pelajaran pendidikan jasmani dilaksanakan di luar ruangan. 
Oleh karena itu dalam melakukan olahraga apakah semua anak tunanetra dari lahir menghadapi kesulitan yang lebih besar? Ini dapat dikaitkan bahwa dari hasil penelitian terdahulu menyatakan resiliensi sebagai salah satu potensi yang berkorelasi dengan keberhasilan akademik pada siswa tunanetra. Untuk itu maka tujuan dari penelitian ini adalah untuk mengetahui resiliensi siswa tunanetra dari lahir dalam berolahraga di Sekolah Luar Biasa (SLB).

\section{METODE}

Studi kasus telah didefinisikan oleh Creswell (1998) as "an exploration of a bounded system or a case (or multiple cases) over time through detailed, in-depth data collection involving multiple sources of information rich in context". Sesuai dengan yang diutarakan diatas metode penelitian yang digunakan melalui pendekatan kualitatif dengan studi kasus yang berusaha memberikan gambaran resiliensi tentang siswa tunanetra dari lahir dalam mengikuti pembalajaran pendidikan jasmani di SLB.

Penelitian dilakukan di SLB Negeri A Citereup Kota Cimahi. Fokus sebagian besar penelitian kualitatif tidak terletak pada generalisasi, karena kasus dibatasi oleh waktu dan aktivitas (Creswell, 2009), maka dari itu pengambilan subjek penelitian ini dengan cara purposive sampling. Sumber data berasal dari kepala sekolah, wakil kepala sekolah, guru pendidikan jasmani, guru kelas, dan 2 siswa tunanetra dari lahir. Sehingga partisipan yang terlibat sebanyak 5 orang partisipan.

Secara umum, wawancara adalah data dasar dengan sumber lain digunakan untuk memvalidasi informasi yang diperoleh dari orang yang diwawancarai (Hancock \& Algozzine, 2011). Hamilton \& Corbett-Whittie (2013) menyarankan menggunakan dua atau lebih sumber atau perspektif itu akan meningkatkan pemahaman tentang studi kasus yang diteliti. Maka dari itu peneliti menggunakan observasi dan wawancara. Dalam penelitian kualitatif peneliti sebagai human instrument sebelum memasuki lapangan telah memiliki catatan mengenai berbagai persiapan, perasaannya, 
harapannya dan pandangannya terhadap dirinya sebagai kunci dalam pengambilan data.

Analisis data dilakukan selama proses penelitian dari awal sampai akhir penelitian dengan bantuan aplikasi NVivo 12 Plus. Pengkodean dalam NVivo 12 Plus dari hasil kajian literatur yang digunakan disebut dengan nodes dan pengkodean hasil wawancara disebut dengan cases. Dalam penelitian kualitatif, tingkat kepercayaan suatu penelitian kualitatif dapat diukur dengan kriteria, yakni credibility, transferability, dependability, dan confirmability. Selain itu untuk lebih meyakinkan tingkat kepercayaan tersebut dengan menggunakan bantuan aplikasi Nvivo 12 Plus for windows. Validitas yang tinggi pula dapat tercapai dengan menggunakan NVivo karena tim penelitian dapat melakukan analisis dengan efektif di NVivo (Bandur, 2019).

Dalam kredibilitas peneliti menggunakan triangulasi. Triangulasi diartikan sebagai pengecekan data dari berbagi sumber dengan berbagai cara, dan berbagai waktu (Sugiyono, 2013). Dalam penelitian ini peneliti menggunakan triangulasi sumber. Triangulasi sumber untuk menguji kredibilitas data dilakukan dengan cara mengecek data yang telah diperoleh melalui beberapa sumber (Sugiyono, 2013). Sumber tersebut didapat dari kepala sekolah, guru dan siswa tunanetra.

Transferability atau transferabilitas merupakan kriteria yang berhubungan dengan apa adanya nilai transfer dari hasil penelitian. Untuk pengujian nilai transfer terletak pada pengungkapan jawaban dari pertanyaan yang berkaitan dengan sejauh mana hasil penelitian ini dapat digunakan atau diaplikasikan dalam situasi lain. Informasi demografi sampel ini berkaitan dengan hasil wawancara yang dilakukan pada kegiatan sehari-hari di sekolah dan aktivitas siswa sehari-hari.

Dependability atau reliabilitas di dalam penelitian ini. Peneliti bertanggung jawab untuk menjelaskan perubahan yang terjadi dalam pengaturan dan bagaimana perubahan ini mempengaruhi cara penelitian mendekati penelitian. Dalam penelitian ini peneliti melakukan wawancara terbuka atau wawancara tidak berstruktur hal ini diharapkan penulis dapat 
secara leluasa menggali data selengkap mungkin dan sedalam mungkin sehingga pemahaman peneliti terhadap fenomena yang ada sesuai dengan pemahaman para pelaku itu sendiri. Jadi peneliti langsung menanyakan permasalah kepada narasumber dengan menggunakan wawancara dan observasi.

Pengujian konfirmability dapat dikatan objektif bila hasil penelitian telah disepakati banyak orang. Untuk dapat memenuhi konfirmability yang berhubungan dengan triangulasi dengan menggunakan semua peneliti dan partisipan.

\section{HASIL}

Dari hasil penelitian yang telah didapat bahwa resiliensi siswa tunanetra dari lahir dalam berolahraga di SLB. Resiliensi dapat dikaji melalui belajar, faktor pendkung, faktor penghambat, motivasi, dan konseling. Dalam melakukan olahraga siswa tunanetra biasanya dalam pembelajaran pendidikan jasmani yang diadakan seminggu sekali.

Guru sebenarnya pada saat mengajar membantu siswa untuk melakukan apa yang guru instruksikan. Sampai siswa disuruh untuk meraba gerak yang dilakukan guru untuk mengikuti, selain itu pendekatan ada yang bersifat klasikal dan individual. Hasil temuan yang peneliti dapatkan di lapangan, berdasarkan hasil wawancara dengan guru pendidikan jasmani, beliau mengatakan bahwa "Ketika disuruh rentangkan tangan jika dia latar belakangnya sudah terbiasa ya bisa tapi jika latar belakangnya dari daerah, gatau rentangkan tangan seperti apa, sama kita kan dipegang dulu, kalo rentangkan tangan tetap tidak bisa, coba pegang bapa di raba-raba seperti apa gerakannya. Raba kan badan kita di belakangnya jadi dia mencari tangan kita. Jadi pelayanannya ada sifatnya individual ada yang sifatnya klasikal, tapi yang dominan itu pelayanan individual". Hasil wawancara dengan guru kelas mengatakan "Kalo di sekolah mah sekali cuma jumat aja" lalu dia berkata kembali "Olahraga jumat disini yah senam, senam ceria terus juga jalan". Kemudian hasil wawancara dengan kepala sekolah mengatakan "Keberagaman anak pun juga mempengaruhinya. Sehingga betul-betul diharapakan sistem 
individual program yang ada itu, betul sesuai dengan kebutuhan anak kadang-kadang guru masih digeneralisir, masih sistem klasikalnya belom spesifik".

Kemudian guru suka memberikan nasihat agar siswa tetap melakukan olahraga, karena dengan olahraga memiliki manfaat selain untuk menjaga kebugaran jasmani. Hasil wawancara dengan guru pendidikan jasmani mengatakan bahwa "Setelah diberitahu sama kita bahwa nih manfaat olahraga tuh itu orang bisa jadi PNS, bisa dapat uang itu salah satunya dari olahraga jadi sekarang pendidikan tidak hanya melalui proses akademik kaya matematika, sejarah dan lainnya". Selain itu sebenarnya orang tua juga harus turut memberikan nasihat kepada anaknya untuk berolahraga, walupun hanya sebatas anjuran saja tanpa memberikan keterangan lebih lanjut apa manfaat dari berolahraga. Hasil wawancara dengan siswa tunanetra mengatakan "Yang menyuruh olahraga biasanya si bapak".

Walaupun sudah mengikuti tetap saja siswa tunanetra tidak menyukai pembalajaran pendidikan jasmani dan mengalami kesulitan dalam melakukan kegiatan pendidikan jasmani. Hasil wawancara dengan siswa tunanetra tidak menyukai olahraga. Hasil wawancara dengan Siti menyatakan "Olahraga tuh pelajaran yang paling kesel. Yang dipelajari, jalan santai terus senam hmm, udah itu aja sih". Selain itu ketika ditanyakan banyak kesulitan dalam pembelajaran pendidikan jasmani dia menjawab banyak kesulitan dan bila diberikan contoh tidak ada suara jadi tidak terlihat. Ditambah dengan perkataan hasil wawancara yang sebelumnya karena bosan olahraganya itu-itu saja. Hasil wawancara dengan siswa tunanetra mengatakan "Banyak (kesulitan), pertama bosen karena olahraga nya kan itu terus itu terus ga ada yang lain". "Terus kalau misalnya kalau senam itu kadang gak ada tutorialnya gak disebutin gerakan-gerakannya itu". "Dicontohin tapi pakai gerakan gak pakai suara, kan gak keliatan kalau kita."

Hal tersebut juga senada dengan apa yang dikatakan oleh guru. Bahwa senam tidak menarik bagi siswa yang dengan mendengarkan 
musik, walaupun diinstruksikan yang penting bergerak juga tidak mau yang akhirnya hanya melakukan olahraga gerak jalan. Hasil wawancara dengan guru pendidikan jasmani mengatakan "Karena mereka punya anggapan, apa lagi kalau musiknya ganti-ganti, seperti poco poco tidak bisa meraka, karena biasanya senamnya pakai hitungan seperti satu rentangkan tangan. Tapi kalo yang musiknya terlalu cepat mereka diam saja, terkadang kata bapa yang penting gerak saja kakinya. Nah jadi itu keluhan ketika mereka senam jadi lebih mengajak gerak jalan saja. Jadi belum ada yang menarik bagi mereka untuk olaharaga senam dengan musik begitu-begitu saja".

Selain dalam proses pembelajaran pendidikan jasmani. Salah satu upaya guru agar siswa tunanetra dengan membawa siswa yang berminat untuk melakukan olahraga di Padjajaran. Guru biasanya berbincang dengan memberikan bimbingan konseling dengan siswa secara individu untuk mengajak siswa melakukan olahraga. Hasil wawancara dengan guru pendidikan jasmani mengatakan,"Ya tadi secara individual diajak ngobrol, kamu bisa apa ? kamu mau apa ? jika suka lari kita arahkan ke padjajaran untuk berlari di sana. Ada goalball juga". Hal senada juga dikatakan oleh guru kelas mengatakan: "Kalo putri lebih senang ke seni seperti nyanyi, main alat musik, kalo laki-laki goalball, lari. Bahkan kalo lari kita langsung ke padjajaran ada pelatihnya di sana". Lebih lanjut lagi hasil wawancara dengan guru pendidikan jasmani mengatakan "Saya sering memberikan agar berprestasi dan raih oleh anda, bahkan sekarang banyak yang nanya "pa kapan ke padjajaran ", "pa kapan latihan lari" kaya begitu".

Pemberian motivasi juga harus dapat diberikan oleg guru pendidikan jasmani. harus bersal dari luar atau guru dapat memberikan kata-kata yang dapat meingkatkan motivasi siswa, hasil wawancara dengan guru pendidikan jasmani mengatakan "Jadi ya begitu tadi motivasinya (bisa jadi PNS dan dapat uang), meraka harus di kasih gambaran, memberikan harapan dan masa depan untuk anak-anak, 
sekarang itu hidup mereka lebih terbuka, memberi motivasi apalagi kalo pemeritah yang mendukung"

Agar dapat terus melakukan olahraga harus didukung juga dengan adanya fasilitas. Fasilitas untuk melakukan kegiatan olahraga di SLB Negeri A Citereup Kota Cimahi sebenarnya cukup memadai dengan adanya lapangan, gedung olahraga, sepada statis. Hasil wawancara dengan siswa tunanetra mengatakan "Fasilitas olahraga lumayan ada lah, gak terlalu gak ada banget". Hal senada dikatakan oleh guru pendidikan jasmani, hasil wawancara dengan guru pendidikan jasmani mengatakan "fasilitas disini lumayan lengkap, kita juga dikasih sepeda statis oleh $\mathrm{Pa}$ Doktor XXXX".

Hasil pengamatan dilapangan siswa tunanetra secara bergantian mencoba menggunakannya sepeda statis pada waktu luang mereka. Hasil wawancara dengan siswa tunanetra ketika ditanya kegiatan olaharga apa yang dilakukan di waktu luang mengatakan "Ya seperti push up, sit up, squat jump, maen sepedah statis". Hal senada juga dikatakan oleh guru pendidikan jasmani, hasil wawancara dengan guru pendidikan jasmani mengatakan "Dulukan belum ada alat-alat olaharaga seperti sepada untuk tunanetra yang di depan itu, jadi setelah ada Pa Doktor XXXX ada fasilitas untuk anak-anak berolahraga".

\section{PEMBAHASAN}

Dari hasil penelitian yang telah didapat bahwa resiliensi siswa tunanetra dari lahir dalam berolahraga di SLB, hanya sebatas mengikuti gerakan yang diinstruksikan oleh guru. Dalam melakukan olahraga guru telah memberikan pembelajaran pendidikan jasmani walaupun hanya sebatas senam dan berjalan yang dilaksanakan dalam seminggu sekali dengan penegasan yang penting siswa tunanetra mau bergerak. Siswa tunanetra memang mengalami kesulitan dalam melakukan kegiatan berolahraga dan mengatakan bahwa bosan olahraganya hanya itu-itu saja. Hasil penelitian terdahulu juga menyatakan bahwa pelajaran olahraga hanya seminggu sekali (Demirturk \& Kaya, 2015). Dari fakta tersebut dapat menimbulkan kurangnya aktivitas fisik anak tunanetra. 
Hasil penelitian terdahulu senada dengan apa yang terjadi di dalam penelitian ini bahwa siswa tunanetra terlihat memiliki keaktifan belajar yang rendah (Setyaningrum, 2017). Anak-anak dan orang dewasa dengan gangguan penglihatan atau kebutaan memiliki tingkat aktivitas fisik yang lebih rendah (Engel-Yeger \& Hamed-Daher, 2013).

Dari kebiasaan sehari-hari siswa tunanetra dan dalam mengikuti pembelajaran pendidikan jasmani, ini memungkinkan tidak akan memenuhi rekomendasi aktivitas fisik yang dianjurkan bahwa aktivitas fisik harus berada pada intensitas sedang ke tinggi. Hasil yang didapat menyatakan bahwa memang benar adanya aktivitas fisik siswa tunanetra tidak dapat memenuhi rekomendasi aktivitas fisik yang telah direkomendasikan. Aktivitas fisik aerobik intensitas sedang hingga tinggi (MVPA) setidaknya 60 menit / hari untuk anak-anak dan setidaknya 150 menit / minggu untuk orang dewasa (WHO, 2010). Total aktivitas fisik harus dapat memenuhi $50 \%$ aktivitas fisik siswa dari sedang ke tinggi dalam pendidikan jasmani (Ginanjar, Suherman, Juliantine, \& Hidayat, 2019). Sehingga hasil penelitian bila disesuaikan dengan rekomendasi aktivitas fisik yang ada penelitian ini mendukung pernyataan bahwa proporsi orang dengan disabilitas mencapai 30 menit aktivitas fisik intensitas sedang pada 5 hari atau lebih per minggu hanya berkisar antara 17,5 hingga 33\% (Stanish, Temple, \& Frey, 2006) dan hasil penelitian tersebut juga belum dapat memenuhi rekomendasi aktivitas fisik.

Walaupun sebenarnya siswa tunanetra mengikuti pembelajaran pendidikan jasmani dengan adanya beberapa hambatan mereka tetap mengikuti kegiatan tersebut dan jika mengalami kesulitan mereka lebih memilih untuk melakukan kegiatan olahraga yang lebih mudah seperti berjalan. Ini berkaitan dengan resiliensi yang dilakukan oleh siswa tunanetra. Hasil tersebut senada dan mendukung dengan hasil penelitian terdahulu yang menyatakan bahwa resiliensi dipandang sebagai suatu sesuatu hal yang wajar untuk diatasi (Ifdil \& Taufik, 2012). Hal tersebut akan berhubungan dengan pernyataan bahwa memerlukan penanganan yang dapat meningkatkan resiliensi agar remaja penyandang cacat fisik 
tersebut memiliki kemampuan untuk bangkit dari permasalahannya (keterbatasan fisik) selama ini (Nurdian \& Anwar, 2014) dan dalam resiliensi terdapat berbagai faktor penghambat seperti keterbatasan penglihatan membuat mahasiswa tunanetra untuk melakukan upaya lebih (Mir'atannisa, 2017).

Kemudian guru dan orang tua sudah seharusnya memberikan nasihat agar siswa tetap melakukan olahraga. Hasil penelitian terdahulu menyatakan nasihat dari orang tua sama pentingnya dengan nasihat dari guru (Widyawan, Ma'mun, Rahely, \& Hendrayana, 2020). Orang tua dapat berbagi informasi penting dan juga dapat memberikan dukungan untuk pendidikan jasmani di dalam dan di luar sekolah (An \& Goodwin, 2007). Selain itu bahwa pendukung utama peserta dalam keluarga mereka adalah ayah (Brunes, Krokstad, \& Augestad, 2017).

Hasil penelitian ini juga memberikan temuan bahwa selain dalam pembelajaran pendidikan jasmani, salah satu upaya guru agar siswa tunanetra dengan membawa siswa yang berminat untuk melakukan olahraga di Padjajaran yang biasanya dilakukan dengan cara bimbingan konseling secara individu untuk mengajak siswa melakukan olahraga. Sehingga, hasil penelitian ini juga mendukung hasil penelitian terdahulu juga menyatakan bahwa pelayanan konseling dan/ atau terapi dapat mengembangkan resiliensi tersebut (Ifdil \& Taufik, 2012), layanan bimbingan maupun konseling yang sesuai untuk membantu meningkatkan resiliensi (Mir'atannisa, 2017). Lebih lanjut lagi, salah satu layanan konseling dapat dengan menggunakan konseling/ bimbingan kelompok (Ifdil \& Taufik, 2012; Nurdian \& Anwar, 2014).

Selain dengan bimbingan konseling, pemberian motivasi juga dapat dijadikan cara untuk siswa tunanetra untuk dapat berolahraga. Sejalan dengan itu hasil penelitian terdahulu juga menyatakan bahwa faktor-faktor yang yang mempengaruhi adversity quotient (yang memiliki pengertian yang sama dengan resiliensi yang merupakan kemampuan yang dimiliki seseorang dalam mengatasi berbagai hambatan) salah satunya motivasi 
(Fikriyyah \& Fitria, 2015), keaktifan belajar siswa dipengaruhi oleh faktor internal salah satunya motivasi belajar (Setyaningrum, 2017).

Hasil penelitian ini juga memberikan temuan bahwa waktu luang dapat dijadikan salah satu cara untuk siswa tunanetra agar dapat berolahraga. Sehingga penelitian ini mendukung hasil penelitian yang menyatakan bahwa aktivitas fisik dapat dilakukan dalam pendidikan jasmani dan aktivitas fisik waktu luang (Lieberman, Robinson, \& Rollheiser, 2006; Solihin, 2020).

\section{KESIMPULAN}

Penelitian ini menyimpulkan bahwa resiliensi siswa tunanetra dalam melakukan olahraga hanya sebatas mengikuti gerakan yang diinstruksikan dan memiliki kesulitan dalam kegiatan olahraga. Dalam hal tersebut upaya-upaya yang dilakukan agar siswa tunanetra dapat terus berolahraga dengan memberikan nasihat, motivasi, bimbingan konseling secara individu, dan melakukan kegiatan olahraga di waktu luang. Temuan peneliti agar lebih memperhatikan kegiatan olahraga dengan mengacu kepada rekomendasi aktivitas fisik yang disarankan dan orang tua agar memberikan dukungan kepada anak agar mau berolahraga dengan memberikan penerangan pentingnya untuk berolahraga.

\section{UCAPAN TERIMA KASIH}

Penulis ucapakan banyak terima kasih kepada seluruh civitas akademik SLB Negeri A Citereup Kota Cimahi yang telah memberikan izin untuk dapat melakukan penelitian.

\section{REFERENSI}

Ahlert, I. A., \& Greeff, A. P. (2012). Resilience factors associated with adaptation in families with deaf and hard of hearing children. American Annals of the Deaf, 157(4), 391-404. https://doi.org/10.1353/aad.2012.1629

Ajuwon, P. M., \& Bieber, R. (2014). Vision impairment and quality of life. Int Public Health, 6(4), 341-354.

An, J., \& Goodwin, D. L. (2007). Physical education for students with spina bifida: Mothers' perspectives. Adapted Physical Activity Quarterly, 24(1), 38-58. https://doi.org/10.1123/apaq.24.1.38 
Bandur, A. (2019). Penelitian Kualitatif Studi Multi-Disiplin Keilmuan dengan NVivo 12 Plus. Jakarta: Mitra Wacana Media.

Brunes, A., Krokstad, E., \& Augestad, L. B. (2017). How to succeed? Physical activity for individuals who are blind. British Journal of Visual Impairment, 35(3), 264-274. https://doi.org/10.1177/0264619617716720

Butler, M. A., Katayama, A. D., Schindling, C., \& Dials, K. (2016). Assessing resilience in students who are deaf or blind: Supplementing standardized achievement testing. The Journal of Educational Research, 111(3), 352-362. https://doi.org/10.1080/00220671.2016.1264052

Creswell, J.W. (1998). Qualitative Inquiry and Research Design: Choosing among Five Tradition. London: Sage Publications

Creswell, J. W. (2009). Research design: Qualitative and mixed methods approaches. London and Thousand Oaks: Sage Publications.

Dahlbeck, D. T., \& Lightsey, O. R. (2008). Generalized self-efficacy, coping, and self-esteem as predictors of psychological adjustment among children with disabilities or chronic illnesses. Children's Health Care, 37(4), 293-315. https://doi.org/10.1080/02739610802437509

Demirturk, F., \& Kaya, M. (2015). Physical education lessons and activity status of visually impaired and sighted adolescents. Medical Science Monitor, 21, 3521-3527. https://doi.org/10.12659/MSM.895038

Engel-Yeger, B., \& Hamed-Daher, S. (2013). Comparing participation in out of school activities between children with visual impairments, children with hearing impairments and typical peers. Research in Developmental Disabilities, 34(10), 3124-3132. https://doi.org/10.1016/j.ridd.2013.05.049

Fikriyyah, W. R., \& Fitria, M. (2015). Adversity quotient mahasiswa tunanetra. Jurnal Psikologi Tabularasa, 10(1), 115-128.

Ginanjar, A., Suherman, A., Juliantine, T., \& Hidayat, Y. (2019). The Effect of Sport Education Model in Badminton Game on Moderate to Vigorous Physical Activity of Junior High School Students. Jurnal Pendidikan Jasmani Dan Olahraga, 4(3), 17-22. https://doi.org/10.17509/jpjo.v4i2.16166

Hamilton, L., \& Corbett-Whittier, C. (2013). Defining case study in education research. Using case study in education research, 3-22.

Hancock, D. R., \& Algozzine, R. (2011). Doing case study research: A practical guide for beginning researchers [Kindle Edition].

Ifdil, I., \& Taufik, T. (2012). Urgensi Peningkatan dan Pengembangan Resiliensi Siswa di Sumatera Barat. Pedagogi: Jurnal IImu Pendidikan, 12(2), 115-121. 
Izzudin, S. A. (2006). Zero to Hero. Yogyakarta: Pro-U Media.

Kaur, G., Leong, T. P., Yusof, J. M., \& Singh, D. (2015). Perception of People with Disability in Creating Sustainable Public Policy. Procedia - Social and Behavioral Sciences, 168, 145-155. https://doi.org/10.1016/j.sbspro.2014.10.220

Lieberman, L. J., Robinson, B. L., \& Rollheiser, H. (2006). Youth With Visual Impairments: Experiences in General Physical Education. Rehabilitation and Education for Blindness and Visual Impairment, 38(1), 35-48. https://doi.org/10.3200/REVU.38.1.35-48

Lupón, M., Armayones, M., \& Cardona, G. (2018). Quality of life among parents of children with visual impairment: A literature review. Research in Developmental Disabilities, 83(January), 120-131. https://doi.org/10.1016/j.ridd.2018.08.013

Mir'atannisa, I. M. (2017). Resiliensi Mahasiswa Tunanetra (Studi Kasus terhadap Mahasiswa Tunanetra tidak dari Lahir di Fakultas IImu Pendidikan Universitas Negeri Yogyakarta). Jurnal Riset Mahasiswa Bimbingan Dan Konseling, 3(3), 309-325.

National Dissemination Center for Children with Disabilities. (2012). Categories of Disability Under IDEA. In Nichcy (Vol. 0285). Retrieved from https://eric.ed.gov/contentdelivery/servlet/ERICServlet?accno=ED 572702\%0Ahttp://www.parentcenterhub.org/wpcontent/uploads/repo_items/gr3.pdf

Nurdian, M. D., \& Anwar, Z. (2014). Konseling Kelompok untuk Meningkatkan Resiliensi pada Remaja Penyandang Cacat Fisik (Difable). Jurnal Ilmiah Psikologi Terapan, 02(1), 36-49.

Rahmati, Z. (2015). The Study of Academic Burnout in Students with High and Low Level of Self-efficacy. Procedia - Social and Behavioral Sciences, 171 , 49-55. https://doi.org/10.1016/j.sbspro.2015.01.087

Setyaningrum, O. (2017). Faktor Penyebab Rendahnya Keaktifan Belajar Anak Tunanetra Kurang Lihat (Low Vision) Kelas 3 Sekolah Dasar Di SLB Negeri 1 Bantul. Jurnal Widia Ortodidaktika, 6(1), 62-73.

Sharma, N., \& Sen, R. S. (2012). Children with Disabilities and Supportive School Ecologies. In M. Ungar (Ed.), The Social Ecology of Resilience: A Handbook of Theory and Practice (pp. 281-295). New York: Springer Science+Business Media.

Solihin, A. O. (2020). Studi Kasus Program Aktivitas Fisik Penyandang Tunanetra. Disertasi. Bandung: SPs UPI Bandung.

Stanish, H. I., Temple, V. A., \& Frey, G. C. (2006). Health-promoting physical activity of adults with mental retardation. Mental Retardation and Developmental Disabilities Research Reviews, 12(1), 13-21. https://doi.org/10.1002/mrdd.20090 
Sugiyono. (2013). Metode Penelitian Kuantitatif Kualitatif dan R\&D. Bandung: Alfabeta.

Ungar, M. (2011). The social ecology of resilience: Addressing contextual and cultural ambiguity of a nascent construct. American Journal of Orthopsychiatry, 81(1), 1-17. https://doi.org/10.1111/j.19390025.2010.01067.x

Ungar, M. (2012). Social Ecoogy of Resilience: A Handbook of Theory and Practice. New York: Springer Science+Business Media.

WHO. (2010). Global recommendations on physical activity for health. Geneva: World Health Organization.

Widyawan, D., Ma'mun, A., Rahely, B., \& Hendrayana, Y. (2020). Parents of students with disabilities views in learning physical education in special needs school. Qualitative Report, 25(4), 924-936. Retrieved from https://nsuworks.nova.edu/tgr/vol25/iss $4 / 3$ 